\title{
Oscilações Intrassazonais Convectivas entre as regiões Indico-Pacífico e o Nordeste do Brasil: Algumas Características Observacionais e de Modelagem
}

\author{
José M.B. Alves ${ }^{1}$, Augusto C.B. Barbosa ${ }^{1}$, Emerson M. Silva ${ }^{1}$, \\ Francisco das C. Vasconcelos Junior ${ }^{2}$, Maria L. da Silva ${ }^{2}$, Antônio C.S. dos Santos ${ }^{1}$, \\ Marcos A.T. Lira ${ }^{3}$, Sérgio S. Sombra ${ }^{1}$ \\ ${ }^{1}$ Departamento de Física, Centro de Ciências e Tecnologia, \\ Universidade Estadual do Ceará, Fortaleza, CE, Brasil. \\ ${ }^{2}$ Fundação Cearense de Meteorologia e Recursos Hidricos, Fortaleza, CE, Brasil. \\ ${ }^{3}$ Universidade Federal do Piaui, Teresina, PI, Brasil.
}

Recebido em 1 de Dezembro de 2017 - Aceito em 2 de Fevereiro de 2018

\begin{abstract}
Resumo
Este estudo investigou com observações e modelagem usando dados diários de Radiação de Onda Longa (ROL) a fase positiva favorável à atividade convectiva associada à variabilidade atmosférica intrassazonal de baixa frequência conhecida com Oscilação de Madden-Julian (OMJ) entre a região do Indico-Pacífico (INDI-PAC) e Nordeste do Brasil (NEB) entre os meses de novembro a maio no período de 1982 a 2013 . O modelo usado foi global OceanLand-Atmosphere Model - OLAMV3.3, e para as observações foram usados dados observados por satélites gerados pelo Climate Prediction Center/National Ocean Atmospheric Admistration. O objetivo foi verificar o tempo do deslocamento da banda zonal dessas oscilações de convecção desde seu pulso inicial, região INDI-PAC até chegar sobre o NEB. Aplicou-se o método de filtragem de dados conhecido como Filtro de Lanczos na banda de 20-70 dias com a finalidade de eliminar oscilações altas (escalas sinóticas) e baixas freqüências (anuais ou mais). Características espectrais usando análises de Ondeletas mostraram que essas oscilações entre 20-70 dias, no período de novembro a maio, têm um espectro de energia máximo nos dados observados centrado no período de 8-16 pêntadas, final de dezembro e início de abril. O OLAM mostrou um adiantamento desse pico de máxima energia na região INDI-PAC e uma extensão na data de chegada no NEB, significando um atraso, sendo essa data para final de abril e maio.
\end{abstract}

Palavras-chave: variabilidade intrassazonal, anos de contrastes, NEB, OLAM.

\section{Convective Intraseasonal Oscillations beteween Indian-Pacific and Northeasth Brazil Regions: Some Observational and Models Characteristics}

\begin{abstract}
This study investigated with observations and modeling using daily data of Long-Wave Radiation (RLW) the favorable phase to the convective activity associated with the low-frequency intrassazonal atmospheric variability known with Madden-Julian Oscillation (MJO) between the Indian Pacific region (INDI-PAC) and Northeastern Brazil (NEB) from November to May period of 1982 to 2013. The model used was the Global Ocean-Land-Atmosphere Model (OLAMV3.3) and observations were used for data generated by satellites by the Climate Prediction Center / National Ocean Atmospheric Admistration. The objective was to verify the time of the zonal band shift of these convective oscillations from its initial pulse, INDI-PAC region until reaching NEB. The data filtering method known as Lanczos Filter was applied in the band of 20-70 days in order to eliminate high oscillations, synoptic scales) and low frequencies (annual or more). Spectral characteristics using Wavelet analyzes showed that these oscillations between 20-70 days, from November to May, have a maximum energy spectrum in the observed data centered in the period of 8-16 pentads, end of
\end{abstract}

Autor de correspondência: José M.B. Alves braboalves@gmail.com. 
December and beginning of April. The OLAM showed an advance of this maximum energy peak in the INDI-PAC region and an extension on the date of arrival in the NEB, meaning a delay, being that date for the end of April and May of this maximum of energy on the NEB.

Keywords: intraseasonal variability, climatic contrasts, NEB, OLAM.

\section{Introdução}

A variabilidade intrassazonal manifesta-se em diversas regiões do globo terrestre, devido à ação de recorrentes fenômenos atmosféricos processando-se em escalas de tempo tipicamente subsazonais (SOUZA et al., 2005). A recorrência temporal de tais fenômenos define se os mesmos são considerados de baixa ou alta frequência. Portanto, em princípio, mecanismos físicos que apresentam uma frequência assídua ou esporádica sobre uma mesma região num determinado período de tempo (dentro de uma estação chuvosa, por exemplo) contribuem para a modulação da variabilidade pluviométrica da região.

A Região Nordeste do Brasil (NEB) é conhecida por apresentar secas severas ou chuvas acima da climatologia (Uvo et al., 1998, Souza et al., 2000), que têm sido relacionados aos padrões anômalos de grande escala da circulação atmosférica global, associado, por exemplo, ao fenômeno El Niño-Oscilação Sul (ENOS). A componente oceânica do ENOS caracteriza-se pela ocorrência do aumento da Temperatura da Superfície do Mar (TSM) no Pacífico Equatorial central e leste anomalamente positiva (El Niño-EN) em uma fase e negativa (La Niña-NA) na fase oposta (Glantz 2001).

A variabilidade interanual de convecção sobre o NEB também está associada às variações dos padrões da TSM sobre o Oceano Atlântico Tropical, os quais afetam a posição e a intensidade do principal sistema meteorológico indutor de chuva no setor norte do NEB, a Zona de Convergência Intertropical (ZCIT), modulando assim a precipitação sobre parte do Nordeste brasileiro (Reboita et al., 2010; Hastenrath e Heller, 1977; Moura e Shukla, 1981, Nobre e Shukla, 1996).

NO NEB, os sistemas atmosféricos atuantes, que impactam a variabilidade pluviométrica na região são sistemas transientes e são modulados também por oscilações intrassazonais. Entre estes citam-se os Vórtices Ciclônicos de Altos Níveis, Sistemas Frontais, Ondas de Leste, Complexos Convectivos de Mesoescala (Coutinho, 2008; Kousky e Gan, 1988; Weickmann et al., 1985; Kousky e Kayano, 1994, Carvalho et al., 2000), Linhas de Instabilidade associadas às brisas marítimas e terrestres (Cavalcanti e Kousky, 1982), assim como instabilidades termodinâmicas locais induzidas por aquecimento diferencial da superfície, convergência de umidade e convecção. Tais fenômenos contribuem para modular a distribuição temporal da precipitação sobre a região, ocasionando longos períodos de estiagem intercalados por ocorrências de precipitações mais abundantes.
Dentre os mecanismos físicos que atuam remotamente impactando o regime de chuva no NEB, interagindo com os sistemas atmosféricos citados acima, está a Oscilação 30-60 dias ou Oscilação de Madden-Julian (OMJ), que consiste basicamente da propagação de uma onda atmosférica na direção zonal (sentido leste) ao longo do globo terrestre e em torno do Equador (Madden e Julian, 1971, 1972 e 1994). Em geral, observa-se uma perturbação nos campos de pressão e convergência de ventos nos baixos níveis, originando a formação de nuvens na escala intrassazonal convectiva, cuja origem se dá sobre o Oceano Índico em direção ao Pacífico oeste. Essa oscilação constitui um dos principais fenômenos de escala intrassazonal capaz de ocasionar variações na convecção de larga escala no Cinturão Tropical (CT) (Yamazaky, 2011, Liebmann et al., 1999; Kiladiz e Mo, 1998; Weng e Lau, 1994 e Kousky e Kayano, 1994, Hendon e Salby, 1994; Kayano e Kousky, 1992 e Kiladiz; Weickmann, 1992; Vicent et al., 1998).

Assim, a OMJ possui grande influência no padrão de nebulosidade sobre a América do Sul (AS), tanto na sua fase positiva, ocasiona uma intensificação da nebulosidade convectiva com uma diminuição de pressão e favorecendo movimento vertical ascendente de ar, quando da sua atuação na fase negativa quando a onda está suprimindo a nebulosidade, e suas características citadas acima são contrárias. Quando a fase positiva está passando sobre a AS, observa-se um aumento da convecção continental, onde pode haver uma conexão com os vários tipos de sistemas atmosféricos atuantes no NEB,. Em alguns anos quando a estação chuvosa do norte do NEB fica normal ou abaixo da média climatológica, a sua influência tornasse mais evidente e modula as variações intrassazonais das precipitações no período de dezembro a maio (Souza e Ambrizzi, 2005).

O objetivo desse estudo foi identificar os períodos da fase da OMJ favorável a atividade convectiva que chega ao NEB saindo da região INDI-PAC, com uso de dados de anomalias de ROL observados por Satélite e comparar com simulações do modelo OLAM, no período de novembro a maio dos anos de 1982-2013. Isto é, identificar nesses anos dentro desses meses os eventos que ocorreram, o tempo necessário desde o inicio do disparo na região INDI-PAC até o momento a convecção chega ao NEB. Os resultados desse estudo poderão dar subsídios a informações ao monitoramento das condições de tempo sobre o NEB nessa escala intrassazonal, para qual o número de estudos ainda é limitado. 


\section{Material e Métodos}

\subsection{Dados usados e método de filtragem}

Para as análises da evolução do sinal da OMJ dados diários de ROL (1982-2013) foram usados na identificação das fases de pulso favorável da atividade convectiva associada à $\mathrm{OMJ}$ desde o momento inicial do disparo no INDIPAC até a região do NEB.

Os dados diários de ROL foram empregados como uma aproximação da atividade convectiva tropical. Esses dados consistem de médias diárias (passagem diurna e noturna) de satélites meteorológicos de órbita polar pertencente à National Oceanic and Atmospheric Administration (NOAA). Maiores detalhes a respeito desses dados podem ser encontrados em Liebmann e Smith (1996). Os dados de ROL estão dispostos numa grade regular cuja resolução horizontal é de $2.5^{\circ} \mathrm{em}$ latitude e longitude no domínio global (144 pontos em longitude e 73 pontos em latitude).

Para identificar essas fases positivas da OMJ, os dados de ROL observados e modelados (OLAM) foram acumulados em 73 pêntadas (médias de cinco dias a partir de 01 de janeiro a 31 de dezembro, com os anos bissextos sendo feito uma média entre os dias 28 e 29). O ciclo sazonal foi retirado com um cálculo de uma média pentadal e suas anomalias, ao longo de cada ano (1982-2013), embora que as pêntadas usadas no estudo compreendam o período entre novembro a maio.

Com o objetivo de eliminar as oscilações transientes com escala de tempo sinótica e as oscilações de mais baixa frequência (sazonal a decadal) das séries temporais analisadas, assim como de evidenciar a variabilidade intrassazonal, foi aplicado o método digital de filtragem conhecido como filtro de Lanczos (Duchon, 1979; Barbosa, 2012), nos dados diários de todas as variáveis citadas anteriormente, antes do acumulo pêntadal das mesmas.

O filtro digital de Lanczos tem como base cálculo da transformada de Fourier, de maneira que as amplitudes de uma série temporal são alteradas através de funções peso, para produzir outra série temporal filtrada numa banda ou frequência desejada. Portanto, seguindo a formulação de Duchon (1979, 1981), o procedimento de filtragem de uma série $\mathrm{X}_{\mathrm{t}}$ consiste em gerar outra série $\mathrm{Y}_{\mathrm{t}}$ através da relação linear.

\subsection{Método para identificar a fase positiva da atividade convectiva}

Para identificar as fases positiva (de atividade convectiva) associadas OMJ e suas relações ao longo dos anos (1982-2013), para as pêntadas de ROL foram calculadas suas anomalias e filtradas na banda de 20-70 dias. As áreas chamadas de controle para o cálculo dessas anomalias pêntadais foram: INDI-PAC $\left(5^{\circ} \mathrm{N}-5^{\circ} \mathrm{S}\right.$ e $\left.75^{\circ} \mathrm{E}-90^{\circ} \mathrm{E}\right)$ e NEB $\left(15^{\circ} \mathrm{S}-2^{\circ} \mathrm{S}\right.$ e $\left.45^{\circ} \mathrm{W}-37^{\circ} \mathrm{W}\right)$.
Após o cálculo dessas anomalias foram feitas algumas considerações, explicadas a seguir, para identificar as fases positivas na região e suas características na região INDi-PAC e sua chegada ao NEB.

A fase positiva de disparo da convecção associada à OMJ na região do INDI-PAC foi considerada quando a anomalia filtrada média de ROL acumulada pêntadal a partir da primeira pêntada de novembro para cada par de anos entre 1982-2013 foi inferior ou igual a $-20 \mathrm{~W} / \mathrm{m}^{2}$.

A pêntada de chegada do pulso do item anterior sobre o NEB foi considerado quando após a pêntada identificada nesse item, à anomalia pêntadal de ROL nas pêntadas subsequentes, sobre o NEB, na primeira dessas for inferior ou igual $-20 \mathrm{~W} / \mathrm{m}^{2}$. Porém para essa pêntada de chegada, embora os dados diários de ROL tenham sido filtrados antes do calculo da anomalia pêntadal, só foi considerada quando o intervalo em dias for igual ou superior a 20 dias entre a pêntada do disparo do pulso na região INDI-PAC e sua chegada ao NEB. A velocidade de fase do pulso foi calculada entre a distância em metros entre a região INDIPAC e o NEB e o tempo decorrido entre a saída do pulso da região INDI-PAC e sua chegada no NEB, transformando os dias em segundos.

Essa consideração foi feita para filtrar possíveis evidências de convecção na região de origem da OMJ com períodos inferiores ao filtro aplicado, que podem estar associados à variabilidade da convecção na região do INDI-PAC não associada à OMJ. Além disso, foram calculadas as pêntadas médias de início e fim dessa fase da OMJ para os anos da fase positiva, nos anos dentre esses considerados de El Niño (EN) e La Niña (LA) e Neutros (NE).

\subsection{Ondeletas e estatística usada no estudo}

Foram usadas também análises de Ondeletas (Morlet, 1982) para identificar as características de sensibilidade do OLAM em simular essas oscilações sobre as regiões do INDI-PAC e NEB.

Para analisar alguns os resultados deste trabalho, foram calculados parâmetros estatísticos como a Média Aritmética simples corresponde ao somatório dos $n$ elementos divididos pelo tamanho $n$ da amostra, coeficiente de variação $(\mathrm{CV})$ e desvio padrão $(\sigma)$, que serve para medir o grau de dispersão das variáveis de uma determinada amostra em torno de um valor central.

\subsection{Modelo usado no estudo}

Para a modelagem numérica da atmosfera optou-se pelo modelo global Ocean-Land-Atmosphere Model (OLAMV3.3), desenvolvido na Duke University (Walko \& Avissar, 2006). Esse MCGA utiliza modernos recursos em sua formulação matemática, possui como principal característica a capacidade de representar fenômenos meteorológicos de escala global, e com o acoplamento de grades refinadas consegue representar de forma mais acurada os fenômenos de escala local e estimar o clima regional (Wal- 
ko e Avissar, 2008). O OLAMV3.3 é uma modificação no núcleo dinâmico do Regional Atmospheric Modeling System (RAMS), com o desenvolvimento de um módulo de domínio global. Também é considerado o novo estadoda-arte em modelagem numérica global em virtude da sua capacidade de refinamento de grade (Walko e Avissar, 2008a, 2008b).

O modelo OLAMV3.3 usa uma grade do tipo não estruturada, em que as células possuem um formato triangular na direção horizontal e, portanto, formam um prisma pentaedral. Esta estrutura de células equilaterais permite preencher totalmente uma esfera, sendo conveniente para a representação da atmosfera terrestre. A triangulação da esfera terrestre se dá através de sua divisão em 20 triângulos equiláteros formando um icosaedro. Cada um destes triângulos originais é subdividido em outros triângulos, permitindo assim, melhoras na resolução espacial. As localizações das grades triangulares não possuem uma distribuição horizontal estruturada.

Esta configuração (não estruturada) requer uma definição da posição destas células através de índices de localização, que são armazenados computacionalmente e posteriormente usados durante a integração numérica. $\mathrm{Na}$ direção vertical, a célula pentaedral é construída através da projeção radial das superfícies da grade triangular a partir do centro da Terra. Desta forma, as faces verticais ficam alinhadas com a força de gravidade, e a área das faces horizontais se expandem gradualmente com a altura.

$\mathrm{O}$ acoplamento dos campos de massa e momento se dá através de uma grade do tipo Arakawa-C. Este tipo de estrutura é um dos mais eficientes computacionalmente, e são convenientes para representação de fenômenos atmosféricos em amplo espectro de escalas. Na presente configuração, os campos de momento são calculados em cada face vertical da célula, e os campos escalares (pressão atmosférica, temperatura, etc.) são estimados pelo seu valor médio volumétrico, e representado no centro do volume desta célula. Esta configuração de grade separa o cálculo de momento em uma componente vertical e outra horizontal.

Outros tipos de modelo possuem estrutura vertical dependentes de projeções das componentes verticais e horizontais no cálculo do momento e, portanto, são menos eficientes computacionalmente. Alta resolução espacial, para alguma região de interesse, pode ser obtida através da divisão das grades triangulares. Este método mantém na mesma localidade as faces do triângulo original da grade de menor resolução. Nas regiões internas, cada grade triangular equilateral é dividido em quatro novos triângulos. Este método evita sobreposição de grades de diferente resolução, portanto não necessita de algoritmos especiais de aninhamento, evita ruídos numéricos, e mantém a conservação de energia. Esta técnica de refinamento permite ilimitado aumento da resolução espacial, incluindo a possibilidade de inserir simultaneamente grades de alta resolução em regiões distintas.
O modelo OLAMV3.3, representa a topografia por um método que assume grades superficiais fracionadas de seu volume original (Adcroft et al., 1997). Este método mantém as superfícies de grade na horizontal, evitando os problemas existentes em outros métodos menos eficientes, em que as grades se ajustam ao terreno e necessitam de projeções especiais de termos verticais e horizontais (Messinger et al., 1988).

A finalidade dos aninhamentos de grades é a possibilidade de uma melhor representação dos processos físicos de pequena escala, os quais são inerentes aos sistemas convectivos que atuam sobre estas regiões (Barbosa, 2012). O OLAMV3.3 considera as leis de conservação de massa, momento e energia interna. Mais especificamente, é considerada a equação de conservação de momento nas direções horizontal e vertical, continuidade de massa, conservação de energia, conservação de outras variáveis escalares, e equação de estado.

As parametrizações físicas adotadas pelo modelo OLAMV3.3 são em sua grande maioria advindas do modelo de mesoescala RAMS (Pielke et al., 1992, Cotton et al., 2003), O modelo considera parametrizações físicas para difusão turbulenta (Mellor e Yamada, 1974), transferências de radiação de onda curta e onda longa (Chen e Cotton, 1987), formação de nuvens e precipitação em suas várias formas liquidas e sólidas (Meyers et al., 1997; Walko et al., 1995), processos convectivos associados a nuvens cumulus (Tremback, 1990) e as trocas de calor sensível e latente entre a superfície e a atmosfera, incluindo várias camadas de solo, e um modelo para o dossel da vegetação (Avissar e Pielke, 1989; Walko et al., 2000). A parametrização de radiação usada nessa simulação foi a de Harrington.

\section{Resultados e Discussões}

\subsection{Resultados com dados de ROL observados por satélite}

As análises a seguir da Tabela 1 e da Fig. 1 mostram os resultados da variabilidade interanual observada (19822013) das datas pentadais dos pulsos positivos de convecção que deixam a região do INDI-PAC e chegam sobre o NEB, e pêntadas médias em anos de La Niña, El Niño e Neutros e para o período de 1982-2013.

A Tabela 1 apresenta os anos entre 1982-2013 em que houve eventos de OMJ com pulso positivo, ou seja, ROL negativo (favorável à atividade convectiva), com início na região de controle do INDI-PAC (pulso inicial) com chegada até o NEB (pulso final).

A primeira coluna são os respectivos anos (com um evento ou mais), as demais representam a pêntada de inicio e a pêntada final de cada evento, e suas velocidades de fase. Aqui se faz uma referência aos valores das pêntadas na Tabela 1, como o estudo tem um período intrassazonal base de novembro a maio, as pêntadas de 1 a 6 , por exemplo, são 
Tabela 1 - Características dos eventos da fase positiva (pèntadas de saída da região INDI-PAC e de chegada na região do NEB, intensidade das anomalias de ROL e velocidade de fase) associados à OMJ dados observados. As anomalias de ROL são acumuladas pêntadais.

\begin{tabular}{|c|c|c|c|c|c|c|c|c|c|c|c|}
\hline Anos & $\begin{array}{c}\text { Pulso }_{i} \\
\text { (Pêntada) }\end{array}$ & $\begin{array}{c}\mathrm{Rol}_{i} \\
\left(\mathrm{~W} / \mathrm{m}^{2}\right)\end{array}$ & $\begin{array}{c}\text { Pulso }_{f} \\
\text { (Pêntada) }\end{array}$ & $\begin{array}{l}\mathrm{Rol}_{f} \\
\left(\mathrm{~W} / \mathrm{m}^{2}\right)\end{array}$ & $\begin{array}{l}\text { Velocidade } \\
\quad(\mathrm{m} / \mathrm{s})\end{array}$ & Anos & $\begin{array}{c}\text { Pulso }_{i} \\
\text { (Pêntada) }\end{array}$ & $\begin{array}{c}\mathrm{Rol}_{i} \\
\left(\mathrm{~W} / \mathrm{m}^{2}\right)\end{array}$ & $\begin{array}{c}\text { Pulso }_{f} \\
\text { (Pêntada) }\end{array}$ & $\begin{array}{l}\mathrm{Rol}_{f} \\
\left(\mathrm{~W} / \mathrm{m}^{2}\right)\end{array}$ & $\begin{array}{l}\text { Velocidade } \\
\quad(\mathrm{m} / \mathrm{s})\end{array}$ \\
\hline 1983 & 8 & $-49,62$ & 11 & $-20,7$ & 14,2 & 1997 & 11 & $-33,43$ & 18 & $-152,14$ & 7,1 \\
\hline 1983 & 16 & $-29,97$ & 23 & $-31,13$ & 7,1 & 1997 & 21 & $-37,36$ & 25 & $-22,58$ & 11,36 \\
\hline 1983 & 27 & $-101,84$ & 30 & $-49,65$ & 14,2 & 1998 & 6 & $-52,76$ & 13 & $-50,44$ & 7,1 \\
\hline 1984 & 8 & $-98,83$ & 14 & $-36,15$ & 8,11 & 1998 & 17 & $-191,9$ & 20 & $-22,77$ & 14,2 \\
\hline 1984 & 21 & $-205,19$ & 25 & $-45,17$ & 11,36 & 1998 & 29 & $-58,99$ & 42 & $-35,45$ & 4,06 \\
\hline 1984 & 38 & $-111,09$ & 42 & $-38,77$ & 11,36 & 1999 & 18 & $-25,33$ & 24 & $-22,85$ & 8,11 \\
\hline 1985 & 14 & $-144,62$ & 21 & $-77,1$ & 7,1 & 2000 & 7 & $-128,87$ & 11 & $-37,97$ & 11,36 \\
\hline 1985 & 27 & $-44,39$ & 36 & $-21,21$ & 5,68 & 2000 & 18 & $-114,73$ & 25 & $-56,39$ & 7,1 \\
\hline 1986 & 14 & $-52,77$ & 17 & $-49,29$ & 14,2 & 2000 & 34 & $-48,8$ & 39 & $-47,24$ & 9,46 \\
\hline 1986 & 26 & $-56,58$ & 29 & $-76,43$ & 14,2 & 2001 & 18 & $-202,96$ & 22 & $-76,78$ & 11,36 \\
\hline 1986 & 32 & $-74,38$ & 35 & $-34,67$ & 14,2 & 2001 & 32 & $-111,53$ & 36 & $-41,55$ & 11,36 \\
\hline 1987 & 5 & $-46,45$ & 9 & $-25,23$ & 11,36 & 2002 & 20 & $-110,57$ & 25 & $-41,5$ & 9,46 \\
\hline 1987 & 18 & $-158,64$ & 39 & $-44,43$ & 2,58 & 2003 & 12 & $-64,65$ & 15 & $-20,87$ & 14,2 \\
\hline 1988 & 6 & $-30,29$ & 19 & $-25,25$ & 4,06 & 2003 & 20 & $-85,71$ & 33 & $-66,12$ & 4,06 \\
\hline 1989 & 28 & $-82,26$ & 34 & $-30,67$ & 8,11 & 2004 & 36 & $-31,13$ & 41 & $-54,35$ & 9,46 \\
\hline 1989 & 38 & $-151,1$ & 42 & $-46,26$ & 11,36 & 2005 & 15 & $-136,5$ & 22 & $-45,52$ & 7,1 \\
\hline 1990 & 5 & $-81,86$ & 9 & $-26,00$ & 11,36 & 2006 & 5 & $-114,45$ & 13 & $-40,48$ & 6,31 \\
\hline 1990 & 19 & $-21,01$ & 32 & $-81,96$ & 4,06 & 2006 & 17 & $-72,75$ & 23 & $-44,53$ & 8,11 \\
\hline 1990 & 37 & $-62,15$ & 42 & $-51,41$ & 9,46 & 2006 & 27 & $-57,39$ & 30 & $-20,2$ & 14,2 \\
\hline 1991 & 28 & $-24,36$ & 31 & $-22,96$ & 14,2 & 2006 & 36 & $-33,5$ & 39 & $-47,38$ & 14,2 \\
\hline 1992 & 8 & $-69,86$ & 24 & $-69,72$ & 3,34 & 2007 & 21 & $-67,64$ & 33 & $-28,26$ & 4,37 \\
\hline 1992 & 28 & $-107,44$ & 33 & $-35,68$ & 9,46 & 2008 & 4 & $-27,38$ & 9 & $-36,9$ & 9,46 \\
\hline 1993 & 17 & $-119,65$ & 21 & $-24,90$ & 11,36 & 2008 & 12 & $-135,17$ & 25 & $-68,13$ & 4,06 \\
\hline 1993 & 31 & $-44,82$ & 36 & $-45,15$ & 9,46 & 2008 & 29 & $-48,14$ & 42 & $-51,99$ & 4,06 \\
\hline 1994 & 26 & $-65,44$ & 31 & $-26,29$ & 9,46 & 2009 & 4 & $-45,55$ & 21 & $-28,22$ & 3,15 \\
\hline 1994 & 34 & $-100,92$ & 37 & $-72,32$ & 14,2 & 2009 & 33 & $-50,71$ & 36 & $-63,1$ & 14,2 \\
\hline 1995 & 7 & $-42,32$ & 12 & $-41,29$ & 9,46 & 2010 & 8 & $-81,92$ & 17 & $-23,04$ & 5,68 \\
\hline 1995 & 18 & $-58,9$ & 28 & $-35,65$ & 5,16 & 2010 & 21 & $-121,79$ & 24 & $-66,66$ & 14,2 \\
\hline 1995 & 33 & $-71,85$ & 38 & $-34,96$ & 9,46 & 2010 & 27 & $-48,55$ & 30 & $-48,9$ & 14,2 \\
\hline 1996 & 22 & $-81,93$ & 28 & $-24,94$ & 8,11 & 2011 & 4 & $-23,31$ & 23 & $-54,21$ & 2,84 \\
\hline 1996 & 36 & $-156,76$ & 42 & $-46,63$ & 8,11 & 2011 & 27 & $-48,62$ & 32 & $-53,22$ & 9,46 \\
\hline
\end{tabular}

relativas ao mês de novembro, enquanto as de 37 a 42 ao mês de maio de cada ano (1982 - representa 1981/1982).

Nota-se por essa Tabela 1, que alguns desses anos tiveram mais um evento entre novembro a maio período de maior atuação da OMJ nessa faixa tropical do globo. Observa-se também que, em todos os anos que ocorreram eventos positivos, e até os anos em que ocorreram mais eventos, em todos os casos há diferenças marcantes nas pêntadas de inicio e final, mostrando grande variabilidade interanual da convecção tropical. Os valores das anomalias negativas de ROL em magnitudes, também variam interanualmente e de evento a evento. Porém, nos eventos que a magnitude é maior na região do INDI-PAC, à medida que o pulso vai caminhando pelo Oceano Pacífico para oeste, adentra o continente diminui seu valor, logo a anomalia de ROL se torna menos negativa, mas ainda assim chega com um valor negativo significativo, indicando uma atividade convectiva no setor norte do NEB.

Outra característica apresentada na Tabela 1 é que as pêntadas de início do pulso positivo na região INDI-PAC nessa variabilidade interanual são de certa forma aleatórias com alguns eventos ao longo desses anos começando na pêntada 4 (final de novembro) e outros até na trigésima oitava pêntada (inicio de maio). Porém em geral, a maior parte das pêntadas de início dos pulsos positivos na região INDI-PAC ocorreu entre a quarta décima pêntada (final de novembro e segunda quinzena dezembro). 


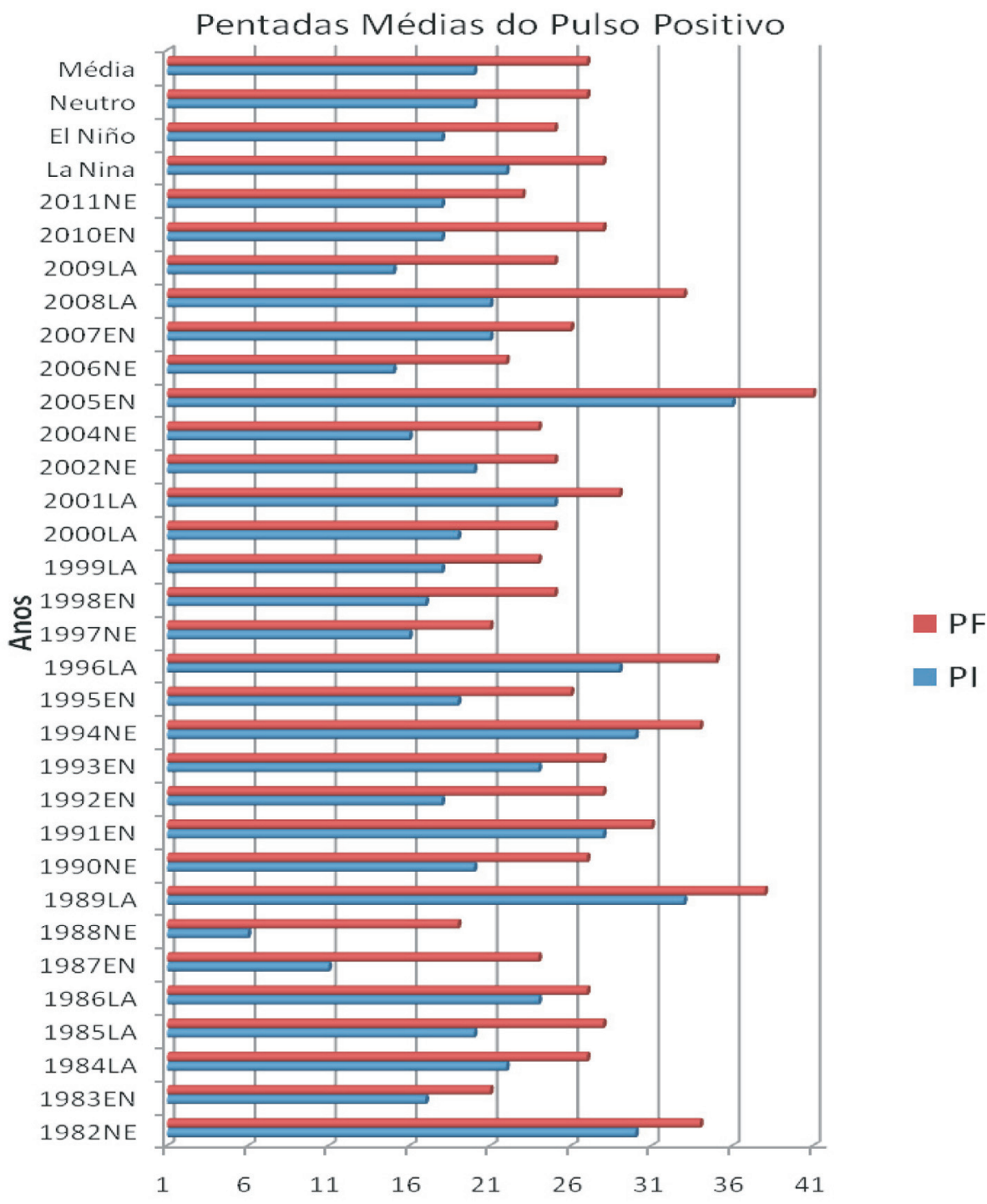

Pêntadas (01 Novembro a 31 de Maio)

Figura 1 - Pêntadas médias de início (PI) na região INDI-PAC e chegada (PF) sobre o NEB do pulso convectivo (fase positiva), associada à OMJ dos eventos da Tabela1, em que ocorreram anos de EN, LA e NE entre 1982-2013 dados observados por satélite. EN, LA e NE significam anos de El Niños, de La Niñas e Neutros (média de todos os anos de El Niño, La Niña e Neutro entre 1982-2013). Média (média dos anos 1982-2013).

Quanto ao período de final (chegada do pulso positivo sobre o setor norte do NEB), os valores pêntadais variaram desde a nona pêntada (meados de dezembro) a quadragésima segunda pêntada (final de maio). Essa característica mostra que há os eventos positivos tem ciclos de início na região do INDI-PAC e fim (sobre o setor norte do NEB) com períodos bastantes variáveis. Essas características também evidenciam uma variação nas velocidades de fase desses pulsos com valores entre 2,58 e $14,2 \mathrm{~m} / \mathrm{s}$, consistentes com velocidades de fase associados à propagação de eventos de OMJ para lestes mostrados em vários estudos com o uso de outras variáveis características da OMJ (Kanutson et al., 1986 e Hendon e Selby, 1994).

A Fig. 1 mostra os valores médios das pêntadas de início e fim no período dos anos que ocorreram eventos positivos de propagação de anomalias de ROL da região INDI-PAC em direção ao setor norte do NEB (anomalias negativas de ROL). Também são apresentados os valores médios com anos de ENOS (anos de El Niño, La Niña e Neutros).

Por essa figura pode-se identificar que os valores médios das pêntadas de início e chegada da convecção associada a fase positiva da OMJ para anos de EN, LA ou NE e todo o período de estudo (1982-2013), oscilaram entre as pêntadas 5-6 (meados final de novembro) e 42-41 (final de maio). Em média, o pulso convectivo associado à OMJ, nessa banda de 20-70 dias, tem início na região do INDIPAC no final de janeiro e início de fevereiro (pêntada 18-20) e chega sobre o NEB em média na pêntada 27 (primeira quinzena de março). Essa característica é consis- 
tente com o período de maior frequência de atuação da OMJ no CT mostrados em alguns estudos que é o verão e outono Austral (Souza et al., 2006).

A Fig. 1 mostra também que em média nos anos de LA o inicio médio do pulso convectivo na região do INDIPAC é um pouco atrasado em comparação com valor pêntadal médio para os anos de EN, $\mathrm{N}$ e a média no período de 1982-2013. Porém, ressaltam-se, alguns anos de EN e NE com essa característica (2005EN e 1982NE). Essa figura mostra que não uma diferença marcante das datas pêntadais de início e fim desse pulso convectivo que sai da região INDI-PAC e sua chegada no NEB; existe sim alguns anos independente de anos de EN, LA ou NE que há grande aletoriedade com eventos saindo mais cedo (tarde) e chegando mais rápido (demorando a chegar) e vice versa no NEB

Outra característica interessante, na Fig. 1, é que apesar do número de anos ser pequeno, episódios de OMJ, nessa banda filtrada de 20-70 dias, em anos NE e de EN, que climatologicamente chove menos e com irregularidade no setor norte do NEB (Nobre e Shukla, 1996), principalmente de fevereiro a maio; os pulsos convectivos, em média, nesses anos tiveram uma velocidade de fase menor, há um período maior entre a pêntada de saída do mesmo da região do INDI-PAC e a sua chegada sobre o setor norte do NEB. Essa característica parece menos evidente, em média, nos anos de LA.

Os resultados a seguir da Tabela 2 e da Fig. 2 mostram os resultados da variabilidade interanual simulada pelo modelo OLAM (1982-2013) das datas pentadais dos pulsos positivos de convecção que deixam a região do INDI-PAC e chegam sobre o NEB, e pêntadas médias em anos de La Niña, El Niño e Neutros e para o período de 1982-2013.

\subsection{Resultados com dados de ROL simulados pelo OLAM}

A Tabela 2 apresenta os anos entre 1982-2012 em que houve eventos extremos de OMJ com pulso positivo, ou seja, ROL negativo (favorável à atividade convectiva), simulados pelo OLAM com início na região de controle do INDI-PAC (pulso inicial) até o NEB (pulso final).

Independentes dos anos nas observações foram encontrados 62 eventos de pulsos negativos, enquanto as simulações do modelo OLAM definiram 29 eventos, subestimando os pulsos de convecção com origem na Região do INDI-PAC que se deslocam em direção ao NEB mais ou menos pela metade. O número de eventos por ano simulados pelo OLAM é inferior aos da Tabela 1.

Na Tabela 2 pode-se observar também, como já visto na Tabela 1, que, em todos os anos que ocorreram eventos positivos, e até os anos em que ocorreram mais eventos, em todos os casos grandes diferenças nas pêntadas de inicio e final (também indicando a grande variabilidade da convecção captada pela parametrização de convecção de Harrington usada no OLAM). Quanto aos valores de ROL há
Tabela 2 - Características dos eventos da fase positiva (pèntadas de saída da região INDI-PAC e de chegada na região do NEB, intensidade das anomalias de ROL e velocidade de fase) associados à OMJ simulados pelo OLAM associados à OMJ. As anomalias de ROL são acumuladas pêntadais.

\begin{tabular}{lccccc}
\hline Anos & $\begin{array}{c}\text { Pulso }_{i} \\
(\text { Pêntada) }\end{array}$ & $\begin{array}{c}\text { Rol }_{i} \\
\left(\mathrm{~W} / \mathrm{m}^{2}\right)\end{array}$ & $\begin{array}{c}\text { Pulso }_{f} \\
(\text { Pêntada })^{2}\end{array}$ & $\begin{array}{c}\mathrm{Rol}_{f} \\
\left(\mathrm{~W} / \mathrm{m}^{2}\right)\end{array}$ & $\begin{array}{c}\text { Velocidade } \\
(\mathrm{m} / \mathrm{s})\end{array}$ \\
\hline 1983 & 34 & $-23,95$ & 37 & $-56,4$ & 14,2 \\
1986 & 10 & $-43,36$ & 13 & $-76,69$ & 14,2 \\
1986 & 34 & $-94,9$ & 41 & $-31,13$ & 7,1 \\
1988 & 12 & $-22,53$ & 15 & $-139,35$ & 14,2 \\
1989 & 14 & $-53,77$ & 33 & $-58,9$ & 2,84 \\
1990 & 23 & $-22,8$ & 29 & $-39,15$ & 8,11 \\
1990 & 34 & $-36,29$ & 39 & $-27,23$ & 9,46 \\
1991 & 10 & $-50,04$ & 42 & $-24,07$ & 1,72 \\
1992 & 23 & $-22,45$ & 29 & $-51,95$ & 8,11 \\
1993 & 21 & $-34,67$ & 26 & $-109,38$ & 9,46 \\
1993 & 32 & $-54,69$ & 37 & $-41,16$ & 9,46 \\
1994 & 4 & $-32,77$ & 9 & $-21,22$ & 9,46 \\
1994 & 25 & $-41,33$ & 29 & $-29,83$ & 11,36 \\
1996 & 13 & $-23,9$ & 24 & $-39,28$ & 4,73 \\
1996 & 33 & $-150,55$ & 37 & $-41,44$ & 11,36 \\
1999 & 6 & $-43,76$ & 20 & $-32,14$ & 3,79 \\
2000 & 7 & $-26,05$ & 35 & $-55,32$ & 1,96 \\
2003 & 4 & $-26,87$ & 15 & $-20,22$ & 4,73 \\
2003 & 24 & $-44,61$ & 29 & $-119,54$ & 9,46 \\
2003 & 34 & $-79,7$ & 37 & $-23,48$ & 14,2 \\
2004 & 4 & $-61,01$ & 15 & $-34,66$ & 4,73 \\
2004 & 27 & $-20,35$ & 31 & $-53,54$ & 11,36 \\
2004 & 35 & $-32,5$ & 39 & $-20,13$ & 11,36 \\
2005 & 10 & $-34,78$ & 31 & $-70,22$ & 2,58 \\
2006 & 5 & $-28,36$ & 33 & $-29,55$ & 1,96 \\
2008 & 7 & $-24,07$ & 32 & $-36,77$ & 2,18 \\
2010 & 13 & $-20,93$ & 35 & $-51,41$ & 2,47 \\
2011 & 9 & $-21,77$ & 29 & $-23,47$ & 2,7 \\
\hline & & & & & \\
\hline
\end{tabular}

pulsos que podem sair com maior (menor) magnitude nas anomalias negativas de ROL na região de inicio do pulso, e chegam ao NEB com valores menor (maior). Em alguns anos essa característica foi verificada também na Tabela 1 para os dados observados de anomalias de ROL.

A característica de grande variabilidade interanual das pêntadas de início do pulso positivo na região INDIPAC também é observada na Tabela 2. Há certa aleatoriedade com alguns eventos ao longo desses anos começando na pêntada 4 (final de novembro) e outros além na trigésima pêntada (para o fim de março). Porém em geral, a maior parte das pêntadas de início dos pulsos positivos na região INDI-PAC ocorre entre a quinta e até décima quinta pêntada (final de novembro a meados de janeiro), mais ou menos similar as observações (Tabela 1). 


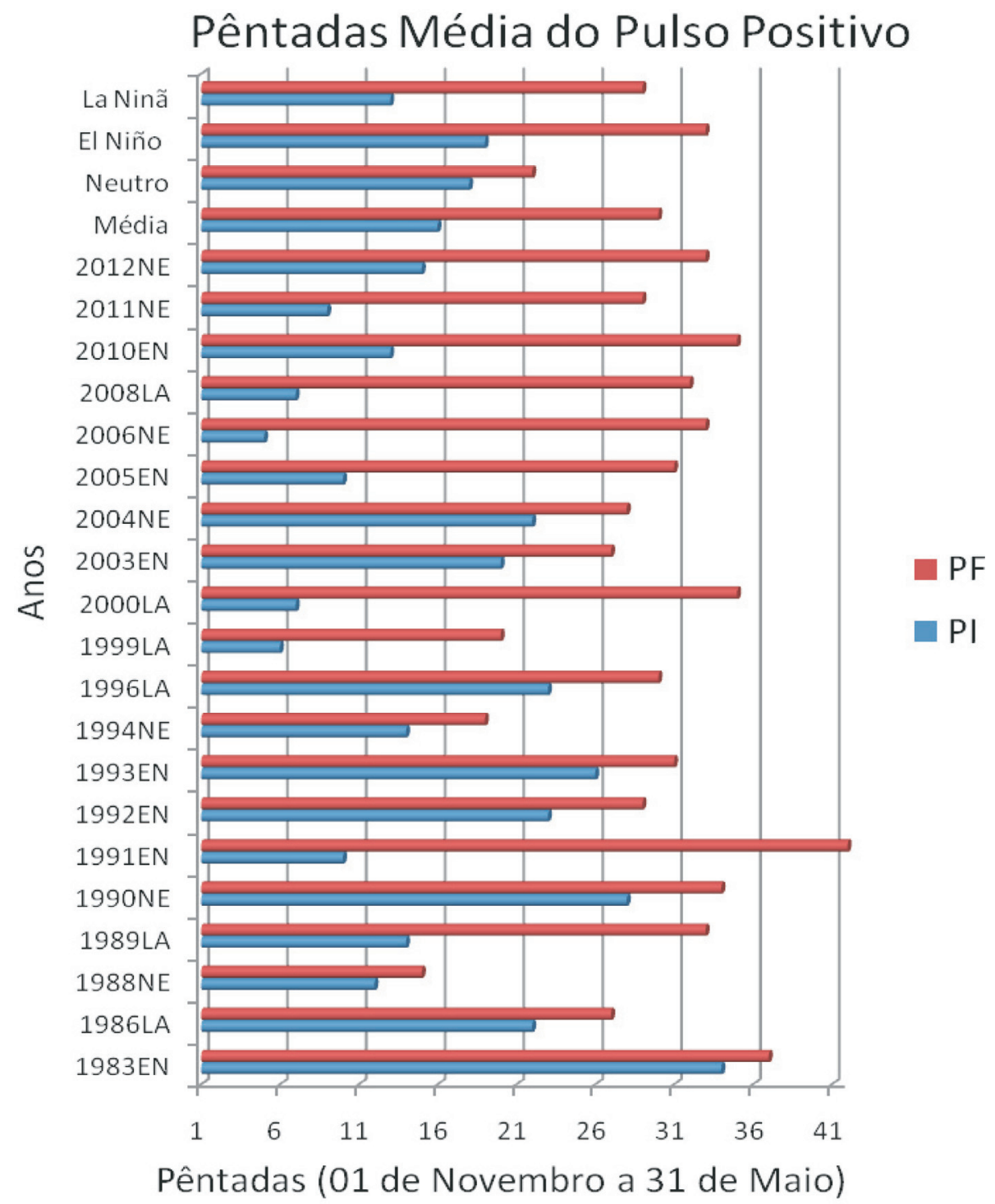

Figura 2 - Pêntadas médias de início (PI) na região INDI-PAC e chegada (PF) sobre o NEB do pulso convectivo (fase positiva), associada à OMJ, simuladas pelo OLAM em que ocorreram anos de EN, LA e NE entre 1982-2013. EN, LA e NE significam anos de El Niños, La Niñas e Neutros (média de todos os anos de El Niño, La Niña e Neutro entre 1982-2013). Média (média dos anos 1982-2013).

Relacionado ao período de final (chegada do pulso positivo sobre o setor norte do NEB), os valores pêntadais variaram desde a nona pêntada (meados de dezembro) a trigésima nona (meados de maio). Porém um pulso destaca-se na simulação do OLAM, o qual deixou a região INDI-PAC no final de dezembro (pêntada 10) e chegou sobre o NEB final de maio (pêntada 42 em 1991). O ciclo de propagação dos eventos positivos simulados pelo OLAM de início na região do INDI-PAC e fim (sobre o setor norte do NEB) teve períodos de duração bastante variados também como observados na Tabela 1 . Em geral, o tempo de saída e chegada desses pulsos positivos simulados pelo OLAM foi um pouco superestimado em relação às observações. Essa característica também evidencia uma maior variabilidade nas velocidades de fase desses pulsos, comparado as observações (Tabela 1) com valores entre
1,20 e $14,20 \mathrm{~m} / \mathrm{s}$. Se compararmos com estudos anteriores de propagação da OMJ, em alguns anos os valores são próximos aos encontrados nos estudos de Kanutson et al., 1986 e Hendon e Selby,1994). Pode-se notar também nessa Tabela 2, comparação com a Tabela 1, que simulações do OLAM em alguns anos mostraram pulsos positivos com convecção que não foram evidentes nos dados de anomalias de ROL observadas por satélites.

A Fig. 2 mostra os valores médios das pêntadas de início e fim no período dos anos que ocorreram eventos negativos de propagação de anomalias de ROL da região INDI-PAC (anomalias positivas de ROL) em direção ao setor norte do NEB para a simulação do OLAM. Também são apresentados os valores médios com anos de ENOS (anos de El Niño, La Niña e Neutros). 
Pode-se identificar que os valores médios das pêntadas de início e chegada da convecção associada a fase positiva da OMJ para anos de EN, LA ou NE e todo o período de estudo (1982-2013), oscilaram entre as pêntadas 5 (final de novembro) e 35 (início de maio). A saída desse pulso positivo e média teve anos na pêntada 4 (final de novembro) e até na 35 (final de abril) mostrando a grande variabilidade interanual da convecção tropical). Em média, o pulso convectivo associado à OMJ, nessa banda de 20-70 dias, tem início na região do INDI-PAC em meados de janeiro (pêntada 15) e chega sobre o NEB em média na pêntada 29 (final de março). Essa característica, também é similar aos dados de anomalias de ROL observadas por satélites (Fig. 1), sendo consistente com o período de maior frequência de atuação da OMJ no CT mostrados em alguns estudos que é o verão e outono Austral (Souza et al., 2006).

A Fig. 2 mostra também nos anos de EN e NE o inicio médio do pulso convectivo na região do INDI-PAC é retardado em comparação com valor pêntadal médio para o período de 1982-2013, ressaltam-se os anos 1990NE, 2004NE, 1983EN e1993EN. Enquanto, nos anos de LA, os resultados simulados pelo OLAM mostram que em alguns houve uma antecipação, principalmente, na ocorrência das pêntadas de início do referido pulso de convecção (a exemplo de 1999).

Outra característica interessante na Fig. 2, já mostradas na Fig. 1, é que os anos NE, têm os pulsos convectivos, em média, com uma velocidade de fase menor, há um período maior entre a pêntada de saída do mesmo da região do INDI-PAC e a sua chegada sobre o setor norte do NEB. Essa característica foi menos evidente, em média, nesses eventos positivos, nos anos de LA. Essa característica para os anos Neutros é similar as observações com o uso de anomalias de ROL (Fig. 1), porém também evidente nos anos de El Niño. Nessas simulações do modelo OLAM há também alguns anos de LA que apresentaram essa irregularidade no deslocamento desses pulsos convectivos.

\subsection{Síntese dos resultados observados e simulados pelo OLAM}

A Fig. 3 sumariza as informações das Tabelas 1 e 2 quanto as pêntadas de ínicio da atividade convectiva na região do INDI-PAC e sua chegada sobre o NEB e suas velocidades de fases, valores médios, para o período de 1982-2013 e anos e contrastes de EN, LA e NE. Nota-se que o OLAM subestima (superetima) as pêntadas de início (chegada) da atividade convectiva nas região INDI-PAC (NEB). Para as velocidades de fases o OLAM tem uma maior variabilidade, em geral, as oscilações desses pulsos de convecção tiverem valores um pouco inferiores as obervações, a execção dos anos Neutros que a velocidade de faze foi da ordem de $10,52 \mathrm{~m} / \mathrm{s}$ superior as obervações em torno de $9 \mathrm{~m} / \mathrm{s}$.

A Tabela 3 mostra os valores do Desvio Padrão (DP) pêntadal dos pulsos dos eventos positivos iniciais e finais (DP PI e DP PF), seus Coeficientes de Variação (CV) e o DP e CV da Velocidade de Fase (VF) desses pulsos para os anos definidos de contrastes climáticos EN, LA e NE e de todos os anos no período de estudo observados pelos dados de ROL estimados por satélite e simulados pelo OLAM (1982-2013).

Os DP e os CV determinam o quão longe e próximos estão da média, respectivamente. O inverso destes dois cálculos é essencial para determinar o grau de significância dos resultados gerados. Por exemplo, se a variável em análise tem DP iguais e próximas, porém com $\mathrm{CV}$ menor ou maior, indica que na segunda distribuição há maior variabilidade em torno da média do que na primeira.

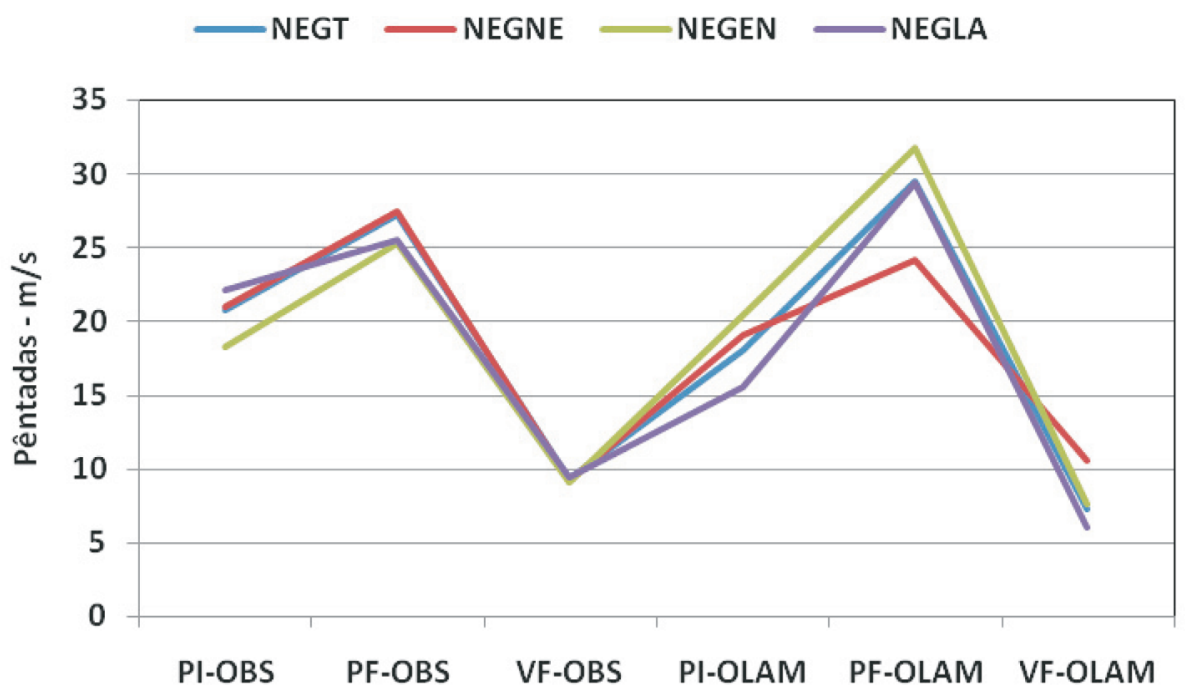

Figura 3 - Pêntadas médias de início (PI) saída da convecção sobre o INDI-PAC e chegada (PF) sobre o NEB para os pulsos positivos (convecção) e suas velocidades de fase médias (VF em m/s) para as observações (OBS) e simuladas pelo OLAM para todo o período (NEGT -1982-2013), para os anos Neutros (NEGNE), para os anos de El Niños (NEGEN) e anos de La Niñas (NEGLA). 
Tabela 3 - Valores do Desvio Padrão (DP) pêntadal dos eventos positivos iniciais e finais (PI e PF) e da velocidade de Fase (VF) e seus Coeficientes de Variação (CV) para os anos definidos de contrastes climáticos EN (El Niño), LA (La Niña) e NE (Neutros) e NEG T (todos os anos 1982-2013). Valores entre parêntese são para a simulação do OLAM.

\begin{tabular}{lcccccc}
\hline & DP PI & CV PI & DP PF & CV PF & DP VF & CV VF \\
\hline NEG LA & $10,20(11,02)$ & $0,54(0,61)$ & $9,90(8,88)$ & $0,40(0,31)$ & $1,17(4,43)$ & $0,26(0,61)$ \\
NEG NE & $10,25(10,60)$ & $0,54(0,59)$ & $11,00(11,80)$ & $0,44(0,41)$ & $1,82(3,87)$ & $0,28(0,53)$ \\
NEG EN & $9,70(10,62)$ & $0,54(0,59)$ & $10,25(7,78)$ & $0,43(0,27)$ & $1,34(4,40)$ & $0,28(0,61)$ \\
NEG T & $10,10(10,64)$ & $0,59(0,83)$ & $10,39(8,84)$ & $0,43(0,30)$ & $1,74(4,29)$ & $0,32(0,59)$ \\
\hline
\end{tabular}

Com relação aos valores de DP e CV das pêntadas de início e fim dos referidos pulsos há um predomínio de desvio padrão da ordem de 10 pêntadas e $\mathrm{CV}$ variando entre 0,40 e 0,57 tanto para a média dos eventos positivos e estes associados aos anos de contrastes climáticos, porém há alguns valores de DP inferiores a 10. Quanto a dispersão em relação à média as menores variações foram nas pêntadas finais dos eventos em anos de $\mathrm{EN}$, e as pêntadas de início dos eventos em anos de EN.

Quanto a velocidade de fase, os DP variaram entre 0,73 a 1,77 (observações de ROL) e 3,01 a 4,40 (OLAM) desvios padrões sendo mais dispersos em relação à média nos anos de eventos positivos em anos de EN (1,27DP). Nesses anos também a simulação do OLAM mostrou desvios padrões mais altos nessa categoria de eventos superior a 4,0, bem maiores em magnitude do que nas observações. Os CV da velocidade de fase oscilaram entre 0,10 e 0,28 , porém esses dados mostram que as oscilações de eventos positivos ocorrentes em anos de LA apresentaram menor variabilidade com DP de 0,73 e um CV de 0,10 .

Para a simulação com o OLAM na velocidade de fase fica evidente um maior $\mathrm{CV}$ em todos os anos de contrastes climáticos, com valores superiores as observações. Em síntese os resultados dessa Tabela 3 mostram que o OLAM teve bom desempenho em simular os valores referentes as pêntadas iniciais, finais e as velocidades de fases dos pulsos positivos de convecção que se deslocam da região INDIPAC e chegam ao NEB. Ressalta-se que houve uma maior variabilidade na velocidade de fase desses pulsos simulados pelo OLAM que são menos evidentes nas observações com ROL estimado com os dados de satélite.

\subsection{Análise Espectral com dados de ROL observados e simulados pelo OLAM}

As Figs. 4 e 5 mostram as características da reposta da Ondeleta de Morlet usada para investigar a sensibilidade espectral da atividade convectiva das anomalias de ROL filtrada na escala de 20-70 dias sobre a regiões do INDIPAC e NEB. Nota-se na Fig. 4 que o modelo OLAM não capturou a energia da variação de ROL na região do INDIPAC no período de 8-16 pêntadas (Fig. 4a) com um máximo de atuação entre final de dezembro e meados de abril (pêntadas 10-33). No OLAM há um máximo de energia entre a 6-7 pêntadas deslocada para esquerda da figura (Fig. 4d), enquanto nas observações esse máximo é mais zonal no período de novembro maio e mais fraco em energia. As variações das oscilações nessa região são mais aleatórias no modelo OLAM (Fig. 4f) do que nas observações onde as fases positivas e negativas são bem sincronizadas (Fig. 4c).

Para a Fig. 5 sobre o NEB, o modelo OLAM não capturou o máximo de energia zonal da variação de ROL no período de 8-16 pêntadas (Fig. 5a) também com um máximo de atuação entre final de dezembro e meados de abril (pêntadas 10-33). No OLAM há um máximo de energia entre a 16-20 pêntadas deslocada para direita da figura (Fig. $5 \mathrm{~d}$ ), fora do cone de influência. As variações das oscilações das anomalias de ROL nessa região são mais aleatórias no modelo OLAM (Fig. 5f), como para a região INDI-PAC, do que nas observações onde as fases positivas e negativas são bem sincronizadas (Fig. 5c). No OLAM há um máximo de energia, em torno da quinta pêntada, com ocorrência predominante entre as 20-30 (início de março meados de abril outono austral), que não aparece nas observações.

\section{Conclusões e Recomendações}

Neste estudo foram usadas simulações climáticas, inicializadas em fim de dezembro de cada ano (1982-2013) do modelo OLAM para investigar a sua sensibilidade a oscilações intrassazonais, com ênfase a escala de 20-70 dias, associadas à atuação da OMJ, em duas áreas: uma de início da oscilação, região do oceano Índico-Pacífico (INDI-PAC) e outra que é impactada pela mesma o Nordeste do Brasil (NEB). Foram escolhidos, os dados de anomalias de ROL observadas e simuladas, que são um "proxy" de ocorrência de precipitação nos trópicos, para identificar as características dos eventos de anomalias de ROL negativas que se formam sobre a região INDI-PAC se propagam para leste e chegam ao NEB. Os principais resultados são mencionados abaixo.

- Há uma alta variabilidade interanual do tempo da ocorrência do pulso convectivo de início da data. Verificou-se 63 pulsos negativos, como datas de início no IND-PAC entre 18 e 20 pêntadas (final de janeiro ou início de fevereiro);

- O OLAM captura aproximadamente este pulso de convecção inicial e chegada. A partir da simulação foi possível identificar 29 pulsos, duas vezes menos do que o 

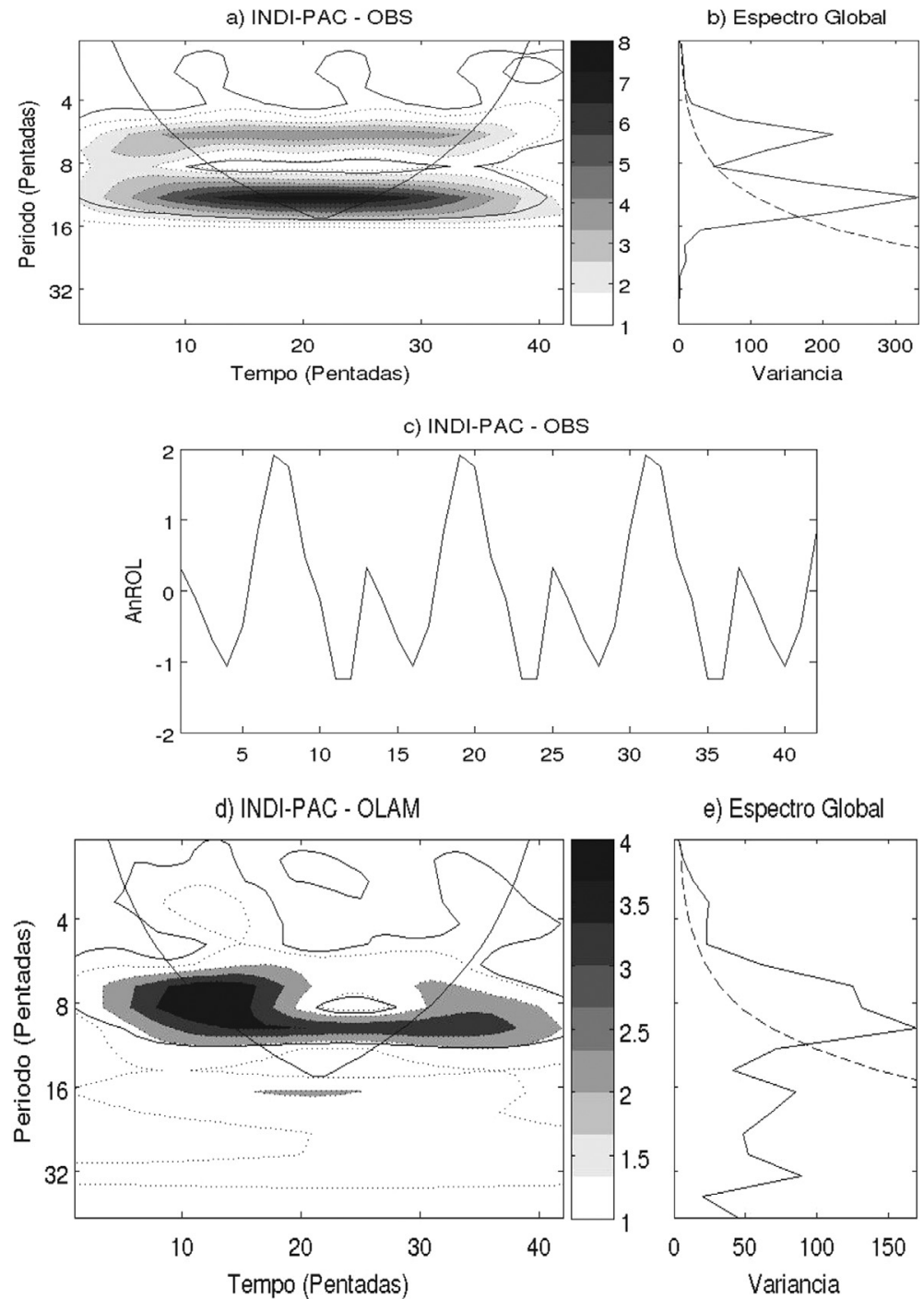

e) Espectro Global

f) INDI-PAC - OLAM

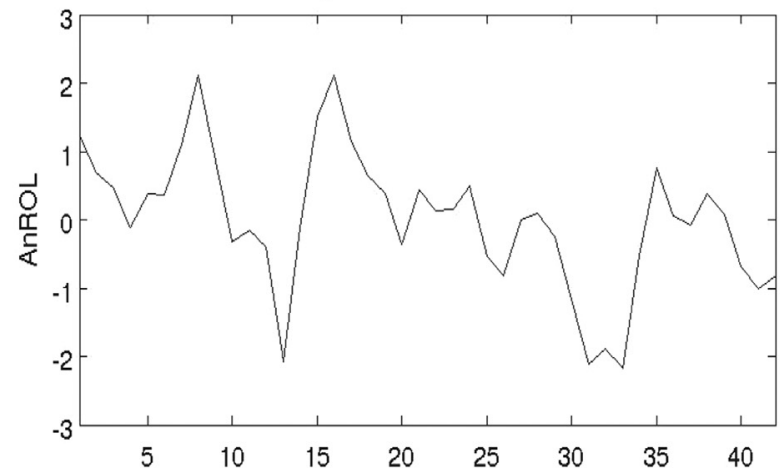

Figura 4 - Características de respostas a Ondeleta para a região do INDI-PAC para as anomalias de ROL observadas e simuladas pelo OLAM, média entre Novembro a Maio (1982-2013). a) Escalograma do espectro de energia $\left(\mathrm{W} / \mathrm{m}^{2}\right)$ OBS, b) Espectro Global $\left(\mathrm{W}^{2} / \mathrm{m}^{2}\right)$ OBS, c) Anomalia de ROL (W/m²) normalizada OBS, d) Escalograma do espectro de energia (W/m ${ }^{2}$ ) OLAM, f) Espectro Global $\left(\mathrm{W}^{2} / \mathrm{m}^{2}\right)$ OLAM, f) Anomalia de ROL (W/m²) normalizada OLAM.

número de pulsos identificados com anomalias observadas de ROL;

- As simulações do OLAM mostraram um adiantamento da convecção na saída da região INDI-PACI e um atraso em relação a sua chegada no NEB comparado as observações;

- - As velocidades de fases das oscilações observadas, entre a saída da região INDI-PAC e sua chegada sobre o 


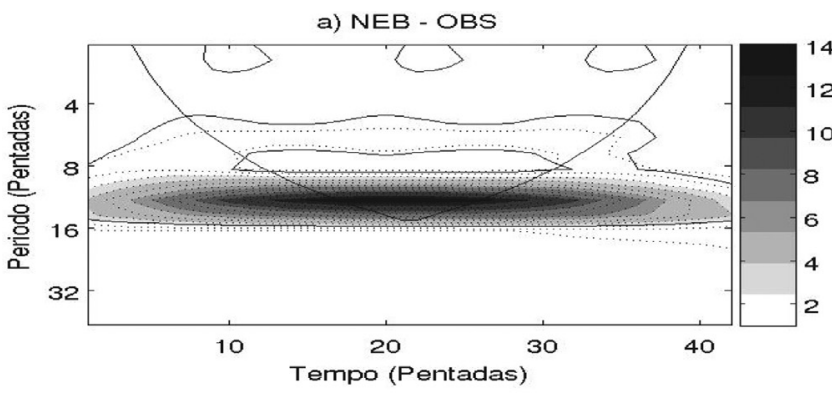

b) Espectro Global
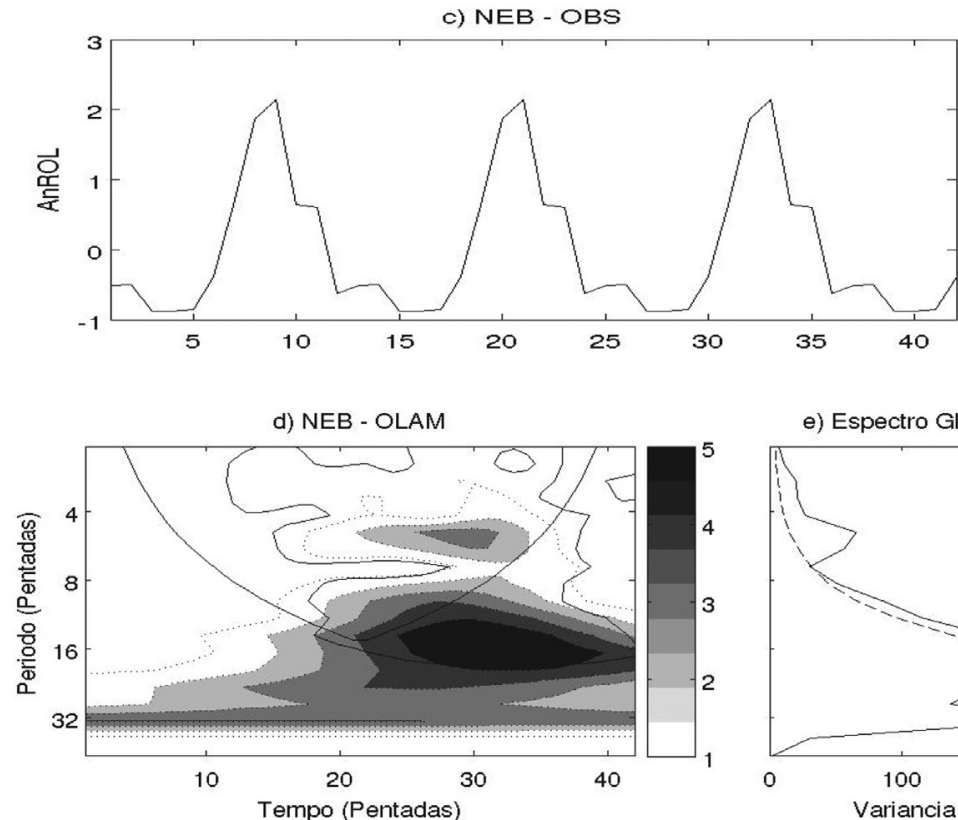

e) Espectro Global

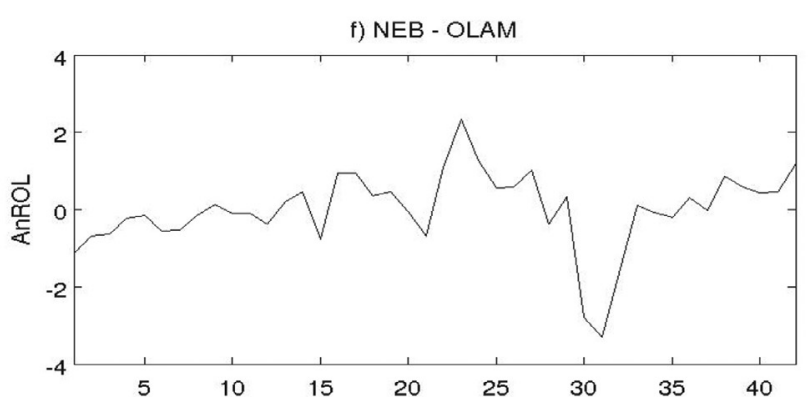

Figura 5 - Características de respostas a Ondeleta para a região do NEB para as anomalias de ROL observadas e simuladas pelo OLAM, média entre Novembro a Maio (1982-2013). a) Escalograma do espectro de energia $\left(\mathrm{W} / \mathrm{m}^{2}\right)$ OBS, b) Espectro Global $\left(\mathrm{W}^{2} / \mathrm{m}^{2}\right)$ OBS, c) Anomalia de ROL (W/m²) normalizada OBS, d) Escalograma do espectro de energia (W/m²) OLAM, f) Espectro Global $\left(\mathrm{W}^{2} / \mathrm{m}^{2}\right)$ OLAM, f) Anomalia de ROL (W/m²) normalizada OLAM.

NEB, embora similares as encontradas pelo modelo OLAM, variando entre 2 a $14 \mathrm{~m} / \mathrm{s}$, em média no OLAM (1982-2013) e para os anos de EL Niño, La Niña e Neutros são da ordem de 3 vezes mais rápidas lentas que as observações;

- Características espectrais mostraram que essas oscilações entre 20-70 dias, no período de novembro a maio, têm um espectro de energia máximo nos dados observados centrado no período de 8-16 pêntadas, com atuação predominante entre final de dezembro e início de abril. O OLAM mostrou um adiantamento desse pico de máxima energia na região INDI-PAC e uma extensão (significando um atraso na chegada da convecção) tendendo para final de abril e maio desse máximo de energia sobre o NEB.

Para estudos futuros sugerem-se comparações entre os resultados da metodologia aplicada no presente estudo, como a metodologia proposta por Mattews $(2000 ; 2008)$, que identifica datas associadas com a propagação MJO 
(fases 1 e 8), e tem representação similar a propagação da convecção do INDI-PAC para o setor da América do Sul.

\section{Agradecimentos}

Aos revisores anônimos da Rbmet pelas contribuições. Esse artigo contém alguns resultados da Dissertação de Mestrado de Maria Leidinice da Silva, apresentada no Mestrado Acadêmico em Ciências Físicas e Aplicadas da Universidade Estadual do Ceará.

\section{Referências}

ADCROFT, A.; HILL, C.; MARSHALL, J. Representation of topography by shaved cells in a height coordinate ocean model. Monthly Weather Review, v.125, n. 9, p. 2293-2315, 1997.

AVISSAR, R.; PIELKE, R.A Parameterization of heterogeneous land surfaces for atmospheric numerical-models and its impact on regional meteorology. Monthly Weather Review, v. 117, n. 10, p. 2113-2136, 1989.

BARBOSA, A.C.B. Oscilações Intrassazonais no INDI-PAC e na Zona de Convergência do Atlântico Sul: Estudo observacional e numérico. 1 v. Doutorado em Meteorologia, IAG, USP, São Paulo, 2012.

CARVALHO, L.M.V.; JONES, C.; SILVA DIAS. M.A.F. Intraseasonal large- scale circulations and mesoscale convective activity in tropical South America during TRMM- LBA campaign. Journal of Geophysical Research, v. 107, n. D20, p. 9-19, 2002.

CHEN, C.; COTTON, W.R. The physics of the marine stratocumulus-capped mixed layer. Journal of the Atmospheric Sciences, v. 44, n.20, p. 2951-2977, 1987.

COTTON, W.R.; PIELKE, R.A.S.R.;WALKO, R.L.; LISTON, G.E.; TREMBACK, C.J.; JIANG, H.; MCANELLY, R.L.; HARRINGTON, J.Y.; NICHOLLS, M.E.; CARRIO, G.G.; MCFADDEN, L.P. RAMS: Current Status and future directions. Meteorology Atmospheric Physics, v. 82, n.1-4, p. 5-29, 2003.

COUTINHO, M.D.L. Método objetivo de identificação dos Vórtices Ciclônicos de Altos Níveis na região tropical sul: validação e climatologia. Dissertação de Mestrado em Meteorologia, Instituto Nacional de Pesquisas Espaciais, São José dos Campos, 119 p, 2008.

DUCHON, C.E. Lanczos filtering in one and two dimensions. Journal of Applied Meteorology, v. 18, n.8, p. 1016-1022, 1979.

GLANTZ, M.H. Currents of change: impacts of El Niño and La Niña on climate and society. $2^{\circ}$ ed. University Cambridge, 252 p, 2001.

HASTENRATH S.; HELLER, L. Dynamics of climatic hazards in northeast Brazil. Quarterly Journal of the Royal Meteorological Society, v. 103, n. 435, p. 77-92, 1977.

HENDON, H.H.; SALBY, M.L. The Life Cycle of the Madden-Julian Oscillation. Journal of the Atmospheric Sciences, v. 51, n.15, p. 2225-2237, 1994.

KAYANO, M. T.; KOUSKY, V.E. Sobre o monitoramento das oscilações intrassazonais. Revista Brasileira de Meteorologia, v 7, n.2, p. 593-602, 1992.

KILADIS, G.N.; WEICKMANN, K.M. Circulation anomalies associated with tropical convection during northern winter.
Monthly Weather Review, v. 120, n. 9, p. 1900-1923. 1992.

KILADIS, G.N.; MO, K.C. Interannual and intreseasonal variability in the Southern Hemipshere Meterol. Monographs, v. 27, n. 49, p. 307-336, 1998.

KOUSKY, V.E.; GAN, M.A. Upper tropospheric cyclonic in the tropical South Atlantic.Tellus, v. 33, p. 538-550, 1988.

KOUSKY, V.E.; KAYANO, M.T. Principal modes of outgoing longwave radiation and $250 \mathrm{Mb}$ circulation for the South American sector. Journal Climate, v. 7, n. 7, p. 1131-1143, 1994.

LIEBMANN, B.; KILADIS, G.N.; MARENGO, J. A.; AMBRIZZI, T. Submonthly Convective Variability over South America and the South Atlantic Convergence Zone. Journal Climate, v. 12, n. 7, p. 1877-1891, 1999.

MADDEN, R.A.; JULIAN, P.R. Detection of a 40-50 day oscillation in the zonal wind in the tropical Pacific. Journal of the Atmospheric Sciences, v. 28, n.5, p. 702-708, 1971.

MADDEN, R.A.; JULIAN, P.R. Description of globalscale circulation cells in the tropics with a 40-50 day period. Journal of the Atmospheric Sciences, v. 29, n.6, p. 1109-1123, 1972.

MADDEN, R.A.; JULIAN, P.R. Observations of the 40-50 day tropical oscillation - A review. Monthly Weather Review, v. 122 , v.5, n.5, p. 814-837, 1994.

MESINGER, F.; JANJIC, Z.; NICKOVIC, S.; GAVRILOV, D.; DEAVEN, D.Z. The step-mountain coordinate: Model description and performance for cases of alpine lee cyclogenesis and for a case of an Appalachian redevelopment. Monthly Weather Review, v. 116, n. 7, p. 1493-1520, 1988.

MEYERS, M.P.; R.L. WALKO; J.Y. HARRINGTON; W.R. COTTON. New RAMS cloud microphysics parameterization 2. The two-moment scheme. Atmosphere Research, v. 45, n. 1, p. $3-39,1997$.

MORLET, J. Wave propagation and sampling theory. Geophysics, v. 47, n.2, p. 222-236, 1982.

MOURA A.D.; SHUKLA, J.On the dynamics of droughts in northeast Brazil: observations, theory and numerical experiments with a general circulation model. Journal of the Atmospheric Sciences, v. 38, n.12, p. 2653-2675, 1981.

NOBRE, P.; SHUKLA, J. Variations of SST, wind stress and rainfall over the tropical Atlantic and South America. Journal Climate, v. 9, n.10, p. 2464-2479, 1996.

PIELKE, R.A.; COTTON, W. R.; WALKO, R. L.; TREMBACK, C. J.; LYONS, W. A.; GRASSO, L. D.; NICHOLLS, M.E.; MORAN, M. D.; WESLEY, D. A.; LEE, T.J.; COPELAND, J.H. A comprehensive meteorological lmodeling systemRAMS. Meteorology Atmosphere Physics, v. 49, n.1, p. 69-91, 1992.

REBOITA, M.S.; GAN. M.A.; Da ROCHA, R.P.; AMBRIZZI, T. Regimes de Precipitação na América do Sul. Uma revisão. Revista Brasileira de Meteorologia, v. 25, n. 2, p. 185-204. 2010.

SOUZA, E.B.; KAYANO, M.T.; AMBRIZZI, T. Intraseasonal submonthly variability over Eastern Amazon and Northeast Brazil during the Autumn rainy season. Theoretical and Applied Meteorological, v. 81, n.3-4, p. 177-192, 2005.

SOUZA, E.B.; KAYANO M.T.; TOTA, J.; PEZZI, L.; FISCH, G.; NOBRE, C. On the influences of the El Niño, La Niña and Atlantic dipole pattern on the Amazonian rainfall during 1960-1998. Acta Amazonica, v. 30, n. 2, p. 305-318, 2000. 
SLINGO, J. M.; SPERBER, K. R.; BOYLE, J. S.; CERON, J.-P.; DIX, M.; DUGAS, B. et. al., Intraseasonal oscillations in 15 atmospheric general circulation models: results from an AMIP diagnostic subproject. Journal of the Atmospheric Sciences, v. 12, n. 5, p. 325-357, 1996.

TREMBACK, C. J. Numerical simulation of a mesoscale convective complex: Model development and numerical results. Ph.D. Dissertation, USA, 1990. 217p.

UVO, C.B.; REPELLI, C.A.; ZEBIAK, S.E.; KUSHNIR, Y.The relationships betweentropical Pacific and Atlantic SST and northeast Brazil monthly precipitation. Journal Climate, v. 11, n. 4, p. 551-562, 1998.

VICENT, D.; FINK, A.; SCHRAGE, J.M.; SPETH, P. High and low frequency Intraseasonal variance of OLR on annual and ENSO timescales. Journal Climate, v. 11, n.5, p. 968-986, 1998.

WALKO, R. L.; COTTON, W.R.; MEYERS, M.P.; HARRINGTON, J. Y. New RAMS cloud microphysics parameterization 1.The single-moment scheme. Atmospheric Reserch, v. 38, n. 1, p. 29-62, 1995.

WALKO, R.L; AVISSAR, R. Predicting hurricane land fall location and timing with The Ocean-Hand-Atmosphere Model (OLAMV3.3). Geophysical Research Abstracts, v. 8, 04344, 2006.

WALKO, R.L.; AVISSAR, R., The Ocean Hand Atmosphere Model (OLAMV3.3): formulation and tests of the no hydro- static dynamic core. Monthly Weather Review, v. 136, n.11, p. 4045-4062, 2008a.

WALKO, R.L.; AVISSAR, R. The Ocean Hand Atmosphere Model (OLAMV3.3): shallow-water test. Monthly Weather Review, v. 136, n.11, p. 4033-4044, 2008b.

WALKO, R.L.; BAND, L.; BARON, J.; KITTEL, F.; LAMMERS, R.; LEE, T.; OJIMA, D.; PIELKE, R.; TAYLOR, C.; TAGUE, C.; TREMBACK, C.; VIDALE, P. Coupled Atmosphere-Biophysics-Hydrology models for environmental modeling. Journal of Applied Meteorology, v. 39, n. 6, p. 931-944, 2000.

WEICKMANN, K.M. Intraseasonal circulation and outgoing longwave radiation modes during northern hemisphere winter. Monthly Weather Review, v. 111, n. 9, p. 1838-1858, 1983.

WENG, H.; LAU, K.M. Wavelet's period doubling, and timefrequency localization with application to organization of convection over the tropical western Pacific. Journal of the Atmospheric Sciences, v. 51, n. 17, p. 2523-2541, 1994.

YAMAZAKI, M. Toward an Understanding of the Madden-Julian Oscillation: With a Mesoscale-ConvectionResolving Model of 0.2 Degree Grid. Advances in Meteorology, v. 2011, 296914, 2011

This is an Open Access article distributed under the terms of the Creative Commons Attribution Non-Commercial License which permits unrestricted non-commercial use, distribution, and reproduction in any medium provided the original work is properly cited. 